\title{
On the Cultural Basis of Gender Differences in Negotiation
}

\author{
Steffen Andersen, Seda Ertac, Uri Gneezy, John A. List and Sandra Maximiano*
}

September 2013

\begin{abstract}
We study the nature versus nurture distinction in bargaining behavior across gender, by observing the negotiation culture in matrilineal and patriarchal societies. Combining data from a laboratory experiment and a natural field experiment conducted in matrilineal and patriarchal societies permits us to explore how culture affects bargaining behavior. One interesting result is that in both the actual marketplace and in the laboratory bargaining game, women in the matrilineal society earn more than men, at odds with years of evidence observed in the western world. We find that this result is critically driven by which side of the market the person is occupying: female (male) sellers in the matrilineal (patriarchal) society extract more of the bargaining surplus than male (female) sellers. In the buyer role, however, we observe no significant differences across societies.
\end{abstract}

JEL: C93, D03, J16.

Keywords: Gender, bargaining, field experiments, culture.

*Andersen: Department of Economics, Copenhagen Business School, Porcelænshaven 16A, 1, DK-2000 Frederiksberg, Denmark (e-mail: sa.eco@cbs.dk); Ertac: Department of Economics, Koc University, Rumeli Feneri Yolu, Sariyer, Istanbul 34450 Turkey (email: sertac@ku.edu.tr); Gneezy: Rady School of Management, University of California, San Diego, 9500 Gilman Drive, La Jolla, CA 92093 (e-mail: ugneezy@ucsd.edu); List: Department of Economics, University of Chicago, 1126 E. 59th St., Chicago, IL 60637, and NBER (e-mail: jlist@uchicago.edu); Maximiano (corresponding author): Economics Department, Krannert School of Management, 403 W. State Street West Lafayette, IN 47907. We would like to thank participants at the 2012 Latin American Meeting of the Econometric Society for helpful comments. 


\section{Introduction}

Many of us hate the back-and-forth of "let me check with my manager" hassles that accompany a visit to car-dealerships. To address this, General Motors' Saturn division made a no-haggle pricing part of its sales pitch in the 1990s. According to Babcock and Laschever (2003), one of the results of this policy was that Saturn cars became very popular with women, who amount to roughly $63 \%$ of the owners of this model. Apparently women like the haggling experience even less than men.

Women's dislike to negotiate is documented by a growing body of survey-based and experimental literature. It is found that women are less likely to initiate negotiations; they report greater anxiety than men about negotiating and are less likely to perceive situations as negotiable (e.g., Bowles, Babcock and Lai, 2005).

This reluctance to negotiate comes with a price, however. For example, Babcock and Laschever (2003) report that women are significantly less likely than men to negotiate the initial compensation offered to them when hired out of business schools - only 7\% of women tried to negotiate, as compared with $57 \%$ of men in their sample. Graduates who did negotiate gained an average of $7.4 \%$ over the initial compensation. This difference is even more important in the long run because even small differences in starting salaries can result in substantial gaps over time (Bowles, Babcock and McGinn, forthcoming; Gerhart and Rynes, 1991; Kray, Galinsky and Thompson, 2002; Stuhlmacher and Walters, 1999). To compound the issue, women tend to be less assertive in negotiations, initially claiming and ending up with a lower surplus (e.g. Kray, Thompson and Galinsky, 2001, Kray and Thompson (2005)).

Why do women fare worse in negotiations than men? One suggested explanation is backlash: it might actually be optimal for women to avoid negotiations or to negotiate less rigorously in situations in which men might benefit from tough negotiating tactics. For example, directive or authoritative leadership style is shown to work against female as compared to male leaders (Eagly, Makhijani and Klonsky, 1992; Eagly and Johnson, 1990). In this spirit, Bowles, Babcock and Lai (2004) show experimentally that participants penalize women job candidates more than men candidates for assertive negotiation behavior (see also Eckel and Grossman, 1996). This explanation is based on the cultural environment ("nurture") in which people negotiate. 
Another suggested explanation for the gender differences in negotiation rests on preferences: women might simply like to negotiate less aggressively than men or do not know when negotiating is appropriate (see, e.g., Croson and Gneezy, 2009; Leibbrandt and List, 2012). Such differences in preferences are reported in related areas. For example, women react less strongly than men to competitive incentives, even when the results of the competition are not publicly announced (Gneezy, Niederle and Rustichini, 2003, Gneezy and Rustichini, 2004, Niederle and Vesterlund, 2007, Gneezy, Leonard and List, 2009), and women are less willing to take on a leading role in decision-making in risky situations (Ertac and Gurdal, 2012).

The preference explanation could have cultural precursors - women and men are raised differently and as a result, their preferences are shaped differently. It could also have an evolutionary basis because of differences in agressiveness that are not unique to humans. For example, a large body of literature in evolutionary biology and socio-biology documents differences in competitiveness between males and females in many species (Darwin (1871); Bateman (1948); and Trivers (1972)). In this paper we approach the nature versus nurture question by studying bargaining behavior in societies with two different sets of gender roles. The first group is the Khasi, which is a matrilineal tribal society where inheritance and economic power flows through the female line. The other group (Kharbi) is patriarchal, with gender roles consonant with those we find in the western world.

Using both a laboratory and a natural field experiment to study bargaining behavior, we observe the negotiation culture in the two groups, permitting us a first test of whether participants from a matrilineal society exhibit different negotiation style than those from a patriarchal society. The field experiment studies bargaining in an actual marketplace, where there is selection into buyer and seller roles, whereas the laboratory experiment implements a well-defined alternating-offer bargaining game where roles are randomly assigned. The use of two different settings with varying selection, control, and observability allows us to explore bargaining behavior and the process of bargaining in a detailed manner. For example, selection is perhaps best illustrated by a fact in the field environment: there are no patriarchal female sellers in the market.

In both experiments, the null hypothesis of no difference in bargaining behavior between the cultures is tested against the alternative that women in the matrilineal society are better at bargaining and/or exhibit more aggressive negotiation. Rejecting the null hypothesis in this case implies that women tend to negotiate worse/earn lower surplus even in societies where there is no social penalty for negotiating (and when the upbringing is more egalitarian than in most societies). 
That is, such a result would be consistent with the notion that the nurture explanation is limited in this situation.

Our main finding is that the "women are inferior bargainers" result of the western world can change crucially in a culture where women enjoy greater economic power and are more involved in economic activity. In both the laboratory experiment and in the actual marketplace, female sellers in the matrilineal society extract more of the bargaining surplus than male sellers. In the lab, where we can make a similar gender comparison with the patriarchal society, we see that this pattern is reversed, and male sellers outperform female sellers. In fact, being a buyer or seller turns out to be an important factor in both the naturally occurring marketplace and the experimental bargaining game: in the buyer role, females in both societies earn similar amounts to males. This result sheds light on the importance of role in extant empirical work and in the market more generally.

The remainder of our paper is structured as follows. Section 2 summarizes or experimental design. Section 3 provides the raw data and inference from the empirical tests. Section 4 concludes.

\section{Experimental Framework}

\subsection{Societal Background}

The Khasi of Meghalaya, Northeast India, are a unique society for studying gender-related questions in the sense that they are one of the few matrilineal and matrilocal tribes that still exist. Lineage and clan membership is traced through the mother, and men reside in their mother's or their wife's home. The household is therefore organized around females, and inheritance goes to the youngest daughter, who continues to live in the house even if she is married. Although Khasi women do not generally assume the roles held by men in patriarchal societies, they always live in households in which their mother has authority over most household decisions. In addition, they enjoy greater economic power than men, since children and property belong to the women. ${ }^{1}$

What is particularly relevant for the issues explored in the current paper is that women are highly involved in economic activity such as selling products in the market, and in fact Khasi women constitute the sole group of female sellers in the marketplace. In the natural field experiment, we contrast the behavior of the Khasi women in the market with male sellers that are non-Khasi

\footnotetext{
${ }^{1}$ For a more extensive discussion on the Khasi society please see Gneezy, Leonard, and List (2009).
} 
(mainly Hindu) and therefore of patriarchal societal origin. In the lab experiment, we contrast the behavior of Khasi males and females with male and female members of the Kharbi tribe, where the social structure is patrilineal and patriarchal. The Kharbi villages in which the experiment was conducted are on the border of Meghalaya and Assam in North East India. These patriarchal villages are geographically close to the Khasi villages, which allow us to achieve greater control in comparisons across the two societies. But, when making comparisons across these societies, we should highlight that other factors might exist to explain the differences that we observe. In this way, we stress that our results are consistent with certain hypotheses, not proving them in any sense of the word.

\subsection{Experimental Design and Procedures}

We conduct two different experiments which complement each other. First, we present a lab experiment in two matrilineal and two patriarchal villages, that is in the spirit of the existing experimental literature on alternating-offer negotiations. This experiment allows us to explore the link between culture and bargaining behavior in a controlled setup with random assignment into buyer and seller roles. In order to see whether the outcomes observed in the lab experiment translate into a field negotiation setting, we next present a natural field experiment in an open market, the Burra bazaar in Shillong, North East India.

\section{A. Bargaining in the laboratory experiment}

The bargaining game in the 'laboratory' involves two players, a buyer and a seller that negotiate over the price of an indivisible good. It is common knowledge that the good has zero value to the seller, and that the buyer is willing to pay a maximum price of 150 for the good. Bargaining proceeds as follows. The seller and buyer simultaneously make a first offer. A coin toss then determines whether the buyer or the seller's first offer is implemented. ${ }^{2}$ In case the seller's (buyer's) offer is implemented, the buyer (seller) either agrees to purchase (sell) the good at the given price or rejects the offer. In case of agreement the game ends. In case of a rejection, nature determines whether the game ends or continues. If the game continues, the buyer (seller) makes a counter offer. The seller (buyer) then accepts or rejects the offer. In case of acceptance the game ends and in case of rejection nature determines whether the game continues or ends. Every time there is a rejection,

\footnotetext{
2 This allows us to observe the initial demands by both parties.
} 
there is an increasing probability that the game ends. In each round this probability equals to r/10, where $r$ is the number of rejections. Therefore, the bargaining game can last up to a maximum of 10 rounds. In case there is no trade, both players receive 0 . In case of trade, the seller's payoff equals $p$ and the buyer's payoff equals $150-\mathrm{p}$, where $\mathrm{p}$ is the agreed-upon price. ${ }^{3}$ As is clear, the laboratory experiment places structure on the bargaining process and implements a finite alternating offer bargaining game.

The experiment was conducted in December of 2008 in four different villages in the Meghalaya district of North East India: two Khasi villages and two Kharbi villages on the Assamese border of Meghalaya. The experimental procedures were the same across societies and villages. Participants were recruited in advance and asked to show up at the village school at a given time. Selection problems were attenuated, given that everyone was interested in participating after learning the pecuniary incentives involved. In total, 320 subjects participated, 166 females and 154 males.

In all treatments, the bargaining room was divided such that sellers were seated on one side of the room while buyers were seated on the other side. The role assignment was done randomly, and the seller and buyer groups could not see each other. While participants did not know whom they were bargaining with, they were made aware of the gender of their bargaining opponent at the start of the bargaining process. Each session had 10 participants, 5 buyers and 5 sellers matched according to their seating order. All buyers had a valuation of 150 Rupees for the good, which was common knowledge. Research assistants who spoke the local language (Khasi for matrilineal villages and Kharbi for patriarchal villages) acted as moderators that took offers back and forth between the two groups. After instructions were read and all the subjects made a first offer, a coin was flipped publicly to decide whether it would be the sellers or the buyers whose first offer would be implemented. In all rounds where a rejection was observed, a 10-sided die was thrown publicly to determine whether play would continue to the next round of bargaining or not.

\section{B. Bargaining in the Field}

\footnotetext{
3 The experiments we ran involved two other treatments, which implemented the bargaining game explained above with subjects bargaining on behalf of a team of two people rather than themselves only. In this paper, we pool the data from all treatments, and use controls for these treatments in our regressions.
} 
We conduct natural field experiments (see Harrison and List (2004)) in one of Asia's largest markets, the open air Burra bazaar in Shillong, North East India. The market is the city's main poultry, meat and produce market. It is built as a myriad of narrow streets, tiny shops and day-today farmers selling their products. The market has many selling agents on each product, and sellers in this market are organized in small geographic locations based on the ethnicity of the sellers as well as the products offered. A unique feature of the market is that the two main ethnic groups represented, the Khasi and Hindu are from a similar historical background, but with a twist in the structure of gender roles. As explained earlier, the Khasi are a matrilineal tribal society and the Hindu are a patriarchal society where the culture is more coherent with gender roles of the western world.

The experiment involved hiring locals as buyer subjects and giving them incentives to bargain toward the purchase of a certain commodity (this approach is in the spirit of the audit study literature, see, e.g., List, 2004). Fourteen locals were hired (16 were hired, but one did not show up and one did not go to the right shops), split between 8 Khasi buyers, 5 males and 3 females, and 6 non-khasi buyers, 3 males and 3 females, to purchase the same commodity at 12 preselected vendors. The vendors were selected to represent 8 Khasi shops, 4 male sellers and 4 female sellers, and 4 non-Khasi male shops. No non-Khasi female shops were selected since none were present in the market at the day of the experiment (out of several hundred sellers).

Buying agents were brought to the market and vendors were discreetly pointed out to the agent, who then made her/his purchase. After the purchase was executed, the agent walked out of the market back to the base of the experimental group located at a nearby restaurant. The purchase was observed at a distance by the chief experimenter, another local Indian. It was recorded whether the right shop was approached and incorrect purchases were discarded from our dataset. We obtained data on 156 purchases.

The commodity chosen was tomatoes, since this was a commonly found item with the shopkeepers, and it was possible to locate several hundred different sellers of tomatoes. Each agent was directed to a pre-selected shopkeeper and instructed to purchase 2 kilograms of 2-day tomatoes on each purchase. ${ }^{4}$ The average price was elicited beforehand to be approximately 14 Rupees, and agents

\footnotetext{
4 Tomatoes were available in a very limited range of quality since one type of tomatoes was sold in the market. The tomatoes were sold in several different degrees of ripeness, and the agents were told to purchase a ripeness degree locally called a ' 2 day" tomato. Purchases were monitored, and failure to buy the right type of tomatoes would result in purchase not being paid for. This did not happen.
} 
were given 30 rupees for each purchase. Any money retained after the purchase was the agent's to keep, and bargaining was therefore incentivized. The on-average extra 16 Rupees was approximately a 30 percent increase in the fixed payment to the buyer subjects. For each purchase we registered the ethnicity of the seller, gender of the seller, initial price quoted by the seller, final agreed-upon price, and the time taken on bargaining. Each buying agent executed several purchases.

\section{Results}

\section{A. Bargaining in the lab}

Experimental earnings for both females and males in the two societies are shown in Figure $1 .{ }^{5}$ Females in the matrilineal society earn on average 56.4 and males 37.0. This difference is significant (Mann-Whitney rank-sum test, $\mathrm{p}=0.005$ ), whereas there is no significant difference in the patriarchal society, where females earn on average 43.6 and males 45.7 .

Data from the patriarchal society changes when we consider market role (see Figure 2 below and table A1 in Appendix A): patriarchal male sellers earn significantly more than patriarchal female sellers (101.56 vs. $60.5, \mathrm{p}=0.005)$. In the matrilineal society, on the other hand, this pattern is reversed: female sellers earn significantly more than male sellers $(74.14$ vs. $36.67, p=0.002)$. There is no significant difference across gender for buyers in either society.

These results are confirmed in a linear regression of earnings on gender, role, society and their interactions (see table A2 in Appendix A). In particular, the regression results show that male sellers earn more than female sellers in the patriarchal society $(p=0.02)$, and male sellers earn less than female sellers in the matrilineal society (Wald test, $p=0.006$ ). None of these results change if we add controls for treatment, or any interactions of treatment with the other independent variables. Moreover, none of the treatment dummies and their interactions is statistically significant. These data lead to a first set of results:

Result 1: Overall, females obtain a significantly larger share of the bargaining surplus than males in the matrilineal society, whereas there is no significant difference in the patriarchal society.

\footnotetext{
${ }^{5}$ In our data, there are initial offers that are larger than 150, the total surplus. Such behavior is likely to have happened because these participants did not understand the game, especially because the observations come predominantly from the patriarchal villages, where a subset of the villagers did not speak the language used in the instructions and had trouble communicating with the experimenters. We therefore exclude these observations in our analyses.
} 
Result 1A: Consistent with the previous literature on Western societies, male sellers in the patriarchal society earn more of the bargaining surplus than female sellers.

Result 1B: The result reverses for the matrilineal society, where female sellers earn more of the bargaining surplus than male sellers.

Next, we investigate the reasons behind these main results. We consider three aspects of the bargaining process: (1) the surplus demanded by each bargaining party, (2) the rejections made and faced by each bargaining party, (3) the size of concessions after rejected offers.

First we explore whether women demand more of the bargaining surplus than men or vice versa in the two societies. We define the "desired surplus" as the initial price asked if the subject is a seller,

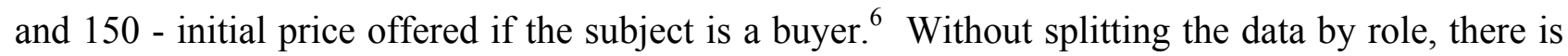
no significant difference between the desired surplus of males and females in either society (see Figure 3).

Figure 4 and Table A3 in the Appendix A show results by role. Independent of society, subjects in the role of sellers demand more of the surplus than subjects in the role of buyers. In the patriarchal society, males in the seller role demand significantly more of the surplus than females in the same role (132.2 vs. $96, \mathrm{p}=0.004)$, whereas there is no significant difference in the matrilineal society, (93.83 vs. 87.41). For buyers, on the other hand, there is no significant difference in the patriarchal society, while male buyers demand more in the matrilineal society $(71.03$ vs. $62.38, p=0.054){ }^{7}$ These data lead us to the next set of results:

Result 2A: Male sellers ask for a higher initial price than female sellers. Differences are statistically significant only in the patriarchal society.

Result 2B: Male buyers ask for a significantly higher initial price in the matrilineal society.

As a consequence of these results, male sellers lose a significantly higher percentage of the surplus that they initially desired compared to females in the matrilineal society $(-61.9 \%$ vs. $-11.5 \%$, $\mathrm{p}=0.000$ ). The differences are neither significant for the patriarchal sellers nor for the buyers in either society (see Table A5. in Appendix A).

\footnotetext{
${ }^{6}$ Recall that we collect initial offers for all subjects independently of whether they actually start the bargaining.

${ }^{7}$ The results of these non-parametric tests are confirmed by regressions presented in Table A4 in the Appendix A. Again, the inclusion of treatment dummies does not change the results.
} 
We now explore the underlying channels for Results 1 and 2. Rejecting received offers, being rejected often, and being less willing to make concessions after rejected offers can all play a role in the finding that bargainers end up with a lower surplus than they demanded. In particular, we investigate whether these mechanisms can explain the findings that male sellers in the matrilineal society end up with lower surplus and the reverse happens in the patriarchal society, with no earnings differences on the buyer side.

We first focus on differences across gender and society in terms of (1) whether a subject rejects the offer he/she receives, (2) whether his/her own proposed offer is met with rejection. Table 1 shows the percentages of rejections made and obtained by subjects who receive and make first offers, respectively. In the patriarchal society, males and females do not display significantly different rejection frequencies of the first offers they receive, although males reject more often $(\mathrm{p}=0.28$ in a two-sided test of proportions). This result in fact becomes significant at $p<.10$ in a probit regression that controls for desired surplus (see Table A6 in Appendix A).

In the matrilineal society, males reject the first offers they receive significantly more frequently than females ( $\mathrm{p}=0.005$ in a two-sided test of proportions). Initial offers made by patriarchal males and females do not have significantly different chances of being rejected, whereas initial offers by matrilineal males are rejected more often $(p=0.04$ in a two-sided test of proportions). Empirical results for being rejected are again upheld in regressions that control for the surplus demanded by the party making the initial offer (see Table A7 in Appendix A). ${ }^{8}$ When we break down by role, we see that in the matrilineal society, male sellers' offers are rejected significantly more than those of female sellers $(76 \%$ of offers made by matrilineal male sellers are rejected, as compared to $35.2 \%$ by females, $\mathrm{p}=0.008$ in a chi2 test). Male sellers in the matrilineal society also reject the offers they receive more than females. In the patriarchal society, there are no such differences in rejections of offers either made or received by male and female sellers. ${ }^{9}$ The data patterns therefore lead to a third set of results:

Result 3: Males reject, and are rejected more, in the matrilineal society, but there is no such difference in the patriarchal society.

Result 3A: Male sellers reject, and their offers are rejected more often, in the matrilineal society.

\footnotetext{
${ }^{8} \mathrm{p}=0.010$ in a Wald test for males rejecting more than females, and $\mathrm{p}=0.06$ in a Wald test for males being rejected more in the matrilineal society.

${ }^{9}$ Likewise, there is no difference in rejection rates of offers made by buyers in either society. However, male buyers in the matrilineal society reject offers more.
} 
Result 3B: There is no difference in rejections of offers made and received by male and female sellers in the patriarchal society.

Finally, we examine the size of the concessions after facing a rejection on their offer by focusing on the percentage adjustment between the 1st (rejected) and 2nd offers (see Figure 1A in Appendix A). Although there are no statistically significant gender differences in any society-role combination at conventional levels, it appears that concessions in addition to rejections can explain part of the results presented above. For instance, female sellers in the matrilineal society are willing to concede more than male sellers $(41.7 \%$ vs. $33.4 \%)$, while male buyers concede more than female buyers $(44.9 \%$ vs. $21.9 \%){ }^{10}$

Overall, these results suggest that the higher surplus earned by female sellers in the matrilineal society is in fact mainly driven by male sellers rejecting, being rejected significantly more, and conceding less on rejected offers than female sellers, which increases the likelihood that they end up with zero surplus $(72 \%$ of male sellers end up with zero earnings in the matrilineal society as opposed to $28 \%$ of female sellers). Alternatively, the higher surplus earned by male sellers in the patriarchal society is not due to differences in rejections, but the higher surplus initially demanded by the males. On the buyer side, although male buyers start with a higher desired surplus, they end up with a similar surplus to female buyers, which is likely due to the larger concession they are willing to make.

\section{B. Bargaining in the field}

When we move from the lab setting to a natural field setting, we are faced with a pool of sellers and buyers that self-select into the market. Gender can be one of the variables that determine this selfselection. In fact, the selection on gender operates strongly enough to lead one group we were able to observe in the lab experiment, the patriarchal female sellers, to be completely absent from the natural market. We therefore have observations based on matrilineal female sellers, matrilineal male sellers and patriarchal male sellers, who are not aware that they are part of an experiment, as well as matrilineal and patriarchal female and male buyers, who, on the other hand, were recruited as experimental participants. The data lead to a first observation:

Observation 1: There are no patriarchal female sellers in the market, due to selection on gender in the patriarchal society.

\footnotetext{
10 The insignificance is likely due to reduced number of observations used in this particular analysis, because we exclude first and second offers that exceed 150. Including these offers does not change the direction of the results.
} 
Given our sample, the first question we explore is how female sellers' bargaining performance compares to males, in terms of their earnings in the market.

Figure 5 shows the initial price offered and the final price obtained by Khasi female sellers compared to Khasi and non-Khasi male sellers. We find that Khasi female sellers end up with a significantly higher final price and therefore a higher bargaining surplus than both Khasi and nonKhasi male sellers (two-sided Mann-Whitney tests, with $=0.02$ and $p=0.00$, respectively), leading to our next result:

Result 4: Khasi female sellers extract more of the available surplus than both Khasi and non-Khasi male sellers.

In order to understand the sources of these differences, we next study: (i) the initial price charged by the seller, (ii) the amount of concession made (the difference between the initial price and the final price, as a percentage of the initial price), (iii) the amount of time taken to reach an agreement.

Comparing the Khasi female sellers to the Khasi male sellers, we find that females' advantage within the matrilineal society arises from demanding a higher initial price $(p=0.01$ in a MannWhitney test), whereas the amount of concession or the time used for bargaining is not significantly different. Comparing the Khasi females to non-Khasi male sellers, these results remain, leading to a next result:

Result 5: Khasi female sellers charge a higher initial price than both Khasi and non-Khasi males.

Khasi female sellers' advantage in bargaining is also reflected in the ability of buyers to negotiate the initial offer made by the seller. When faced with a Khasi female seller, only $69 \%$ of buyers are able to move the price, whereas $81 \%$ of buyers faced with any other type of seller successfully gain any concessions ( $\mathrm{p}=0.09$ in a two-sided test of proportions). This leads to a sixth insight:

Result 6: Although the average amount of concessions is not different, Khasi females' initial offers are more likely to be accepted without negotiation. ${ }^{11}$

In order to account for the fact that we have multiple observations from the same sellers, and to explore whether the gender and ethnicity pairing of the buyer and seller affects the bargaining measures outlined above, we run a series of random-effects regressions of initial and final price,

\footnotetext{
11 This result may be either due to the unwillingness of the Khasi female sellers to move their sale price down, or due to the reluctance of the buyers to attempt to negotiate with a Khasi female.
} 
reported in Table 2. Regression models 1 and 3 show that Khasi females charge a significantly higher initial price and obtain a higher final price; therefore, Results 4 and 5 are robust when we control for dependence. The results also remain when we additionally control for buyer characteristics and their interaction with seller characteristics (Models 2 and 4). ${ }^{12}$

Although buyers in our experiment know that they are part of an experiment, and are not the focus of our analysis, it might be insightful to explore whether matriliny makes a difference in the buyer sample. An important measure of bargaining performance for the buyers is the difference between the initial price quoted by the seller and the final price paid by the buyer.

Using this measure, we find that Khasi female buyers are not significantly different than Khasi male buyers, in the sense that they achieve similar percentage-point concessions from the seller's initial price (Mann Whitney test, $\mathrm{p}=0.24$ ). The initial prices they are quoted are not different either $(p=0.99)$. Moreover, Khasi female buyers are not more likely than Khasi male buyers to reject the initial price quoted by the seller $(\mathrm{p}=0.85)$. Comparing Khasi female buyers to non-Khasi (patriarchal) female or patriarchal male buyers, we again find no significant differences in behavior along these dimensions. It is interesting to note that patriarchal males and females do not exhibit significant differences in the buyer role either, in terms of initial price and the initial-final price difference. This leads to our final result:

Result 7: In the buyer role, there are no significant differences between males and females in either society.

\section{Discussion}

Whether, and to what extent, societal forces influence propensities to bargain and resource allocations from those bargains is of first order import. By exploring behaviors across the lab and the field in societies that are characterized as nearly polar opposites in the treatment of women, we are permitted a unique glimpse into one case study on those bargaining differences. Our data collection strategy allows for a rich set of results because synergies between the lab and the field allow us to make inferential statements that we could not make if we had each experiment in

\footnotetext{
${ }^{12}$ In the model for final price, the only (weakly) significant coefficient in terms of the gender and ethnicity pairing of the buyer and the seller is Khasi female sellers bargaining against Khasi female buyers. A Wald test shows that Khasi female sellers end up with a significantly higher price than non-Khasi male sellers when the buyer is a Khasi female $(p=0.01)$. None of the gender/ethnicity pairing variables are significant in regressions of initial price.
} 
isolation. However, an important caveat is that our work can only shed preliminary insight into this issue, as several other factors might underlie our findings. In this light, our results should be viewed as merely a first attempt at estimating the importance of societal forces on bargaining proclivities and outcomes.

With that caveat in mind, our main result is that matrilineal females earn more surplus in bargaining than matrilineal males, which provides evidence consistent with the notion that women do not have an inherent, natural disadvantage in bargaining, and that bargaining outcomes across gender can be crucially culture-dependent. The data also highlight that the particular role in the marketplace might be critical to the results. Given that Khasi females act frequently as sellers in the actual marketplace and non-Khasi females only have experience in the buyer role, the results that (1) female sellers earn more than male sellers in the matrilineal society, with the reverse happening in the patriarchal society, and (2) females earn similar surplus to males in the buyer role in both societies (weakly higher surplus in the matrilineal society) suggest that subjects carry over insights from their daily economic experience into the lab setting.

While in terms of earnings matrilineal women do better than men in both experimental domains, we find that women do not use the same strategies in reaching their outcomes. An important difference between bargaining in the actual market and bargaining in the lab is that risk likely plays a bigger role in the latter. Since there is a probability that the game ends and the surplus is destroyed, being a tough bargainer can be a more detrimental strategy than in actual face-to-face bargaining. ${ }^{13}$ Although matrilineal female sellers act tougher in the actual market, they start with a lower demand and reject less in the bargaining lab game. This behavior by women could be due to a better understanding that the nature of the game is different, or due to higher risk aversion. In contrast to females, matrilineal males ask for more, and their offers are more frequently rejected even after controlling for demanded surplus; this leads to them getting a lower surplus in bargaining.

Finally, the fact that women's offers are rejected less often in the matrilineal society (controlling for the demanded surplus) might suggest that female sellers in the actual marketplace can afford to be tough. Since actual trading in the marketplace is face-to-face and does not end exogenously, matrilineal women might have a better environment to exercise or try out high demands, and a norm

\footnotetext{
${ }^{13}$ In fact, there is research that shows that the mode of communication (face-to-face vs. non-face-to-face) and anonymity can crucially affect negotiation outcomes, with anonymous and non-face-to-face communication often leading to less "integrative" outcomes (e.g. Stuhlmacher and Citera (2005))
} 
of female sellers being tougher bargainers might have evolved. In the laboratory, on the other hand, caution may prevent them from applying such a strategy.

In conclusion, our paper provides a first exploratory analysis of how culture might impact alternating-offer bargaining behavior. One interpretation is that the matrilineal culture economically empowers women and gives them an active role in economic transactions, which results in a payoff advantage for women in two different types of bargaining contexts. Giving women more experience in bargaining or related monetary decisions might therefore be quite conducive to enhancing outcomes. Further research is needed to more fully explore the effects of culture and other structural variables on the interaction of gender and bargaining outcomes. 


\section{References}

Babcock, L., and Laschever, S. (2003). Women don't ask. Princeton, NJ: Princeton University Press.

Babcock, L., Gelfand, M., Small, D., and Stayn, H. (2006). Gender differences in the propensity to initiate negotiations. In D. D. Crèmer, M. Zeelenberg \& J. K. Murnighan (Eds.), Social Psychology and Economics (pp. 239-259). Mahwah, NJ: Lawrence Erlbaum.

Bowles, H.R., Babcock, L., \& McGinn, K. L. (2005). Constraints and triggers: Situational mechanics of gender in negotiation. Journal of Personality and Social Psychology, 89: 951965.

Croson, R. and Gneezy, U. (2009). Gender Differences in Preferences. Journal of Economic Literature, 47 (2): 1-27

Eckel, C., and Grossman, P. (2008). Differences in the economic decisions of men and women: Experimental evidence. In C. Plott, V. Smith (Eds.), Handbook of results in experimental economics

Ertac, S. and Gurdal, M Y. (2012). Deciding to Decide: Gender, Leadership and Risk-Taking in Groups. Journal of Economic Behavior and Organization, in press.

Gerhart, B., and Rynes, S. (1991). Determinants and consequences of salary negotiations by male and female MBA graduates. Journal of Applied Psychology, 78: 256-262

Gneezy, U., Niederle, M., and Rustichini, A. (2003). Performance in Competitive Environments: Gender Differences. Quarterly Journal of Economics, 118(3): 1049-74.

Gneezy, Uri, and Aldo Rustichini. 2004. "Gender and Competition at a Young Age." American Economic Review, 94(2): 377-81.

Gneezy, U, Leonard, K.L. and List, J.A. (2009) "Gender Differences in Competition: Evidence from a Matrilineal and a Patriarchal Society." Econometrica, 77, 5, 1637-1664.

Harrison, G. W. and List, J. A. (2004) Field Experiments. Journal of Economic Literature, 42 (4), 1009-1055.

Kray, L., Thompson, L., and Galisnsky,A. (2001). Battle of the sexes: Gender stereotypes and reactance in negotiations. Journal of Personality and Social Psychology, 80: 942-958.

Kray, L. J., Galinsky, A. D., and Thompson, L. (2002). Reversing the gender gap in negotiations: An exploration of stereotype regeneration. Organizational Behavior and Human Decision Processes, 87: 386-410.

Leibbrandt, A. and List, J.A. (2012). Do Women Avoid Salary Negotiations? Evidence From a Large-Scale Natural Field Experiment, NBER working paper \# 18511. 
List, J.A. (2004). "The Nature and Extent of Discrimination in the Marketplace: Evidence from the Field," Quarterly Journal of Economics, , 119(1), pp. 49-89.

Niederle, M. and Vesterlund. L. (2007). Do Women Shy Away from Competition? Do Men Compete Too Much?" Quarterly Journal of Economics, 122(3): 1067-1101.

Stuhlmacher, A. F., and Citera, M. (2005). Hostile behavior and profit in virtual negotiation: A metaanalysis.Journal of Business and Psychology, 20, 69-93.

Stuhlmacher, A. And Walters, A. (1999). A. Gender differences in negotiation outcomes: A metaanalysis. Personnel Psychology, 52: 653-677. 


\section{FIGURES}

Figure 1: Final surplus, by gender and society (lab experiment)

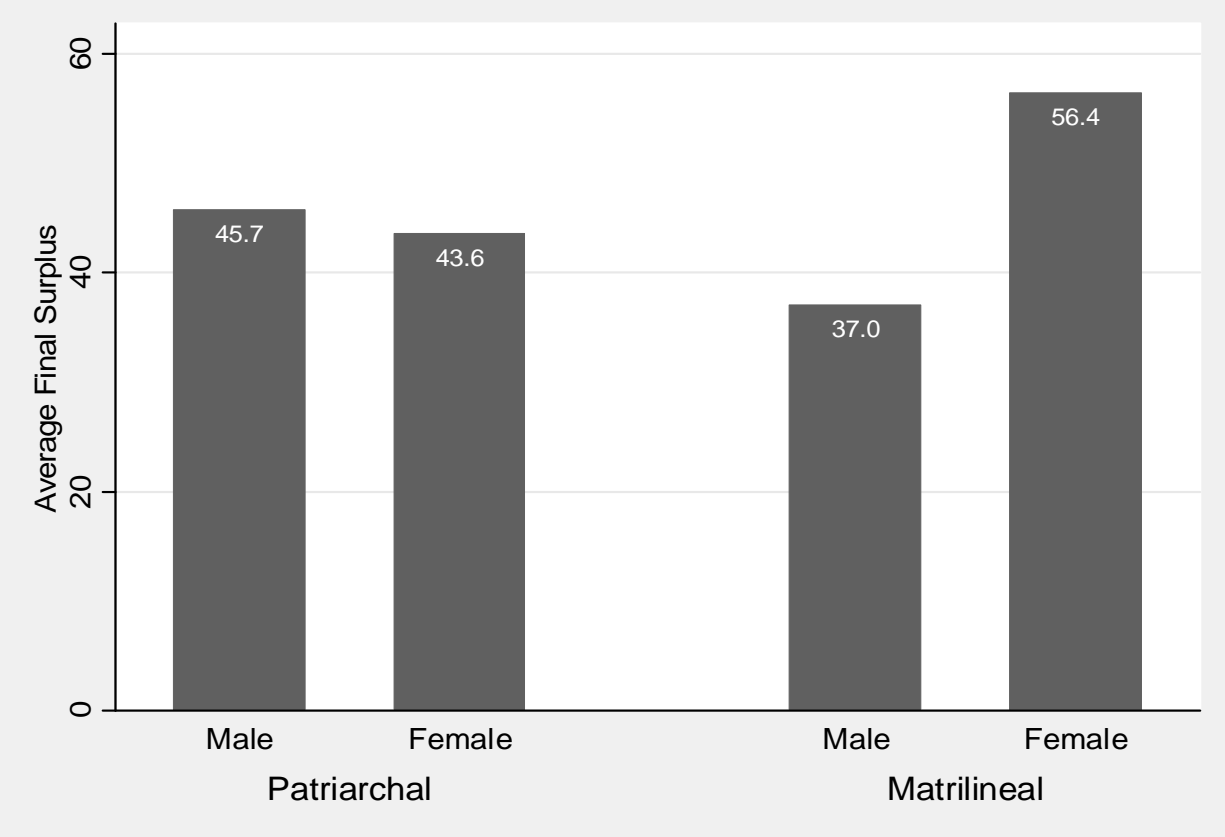

Note: Average final surplus is defined as final earnings for subjects in rupees.

Figure 2: Final surplus by gender, society, and role (lab experiment)

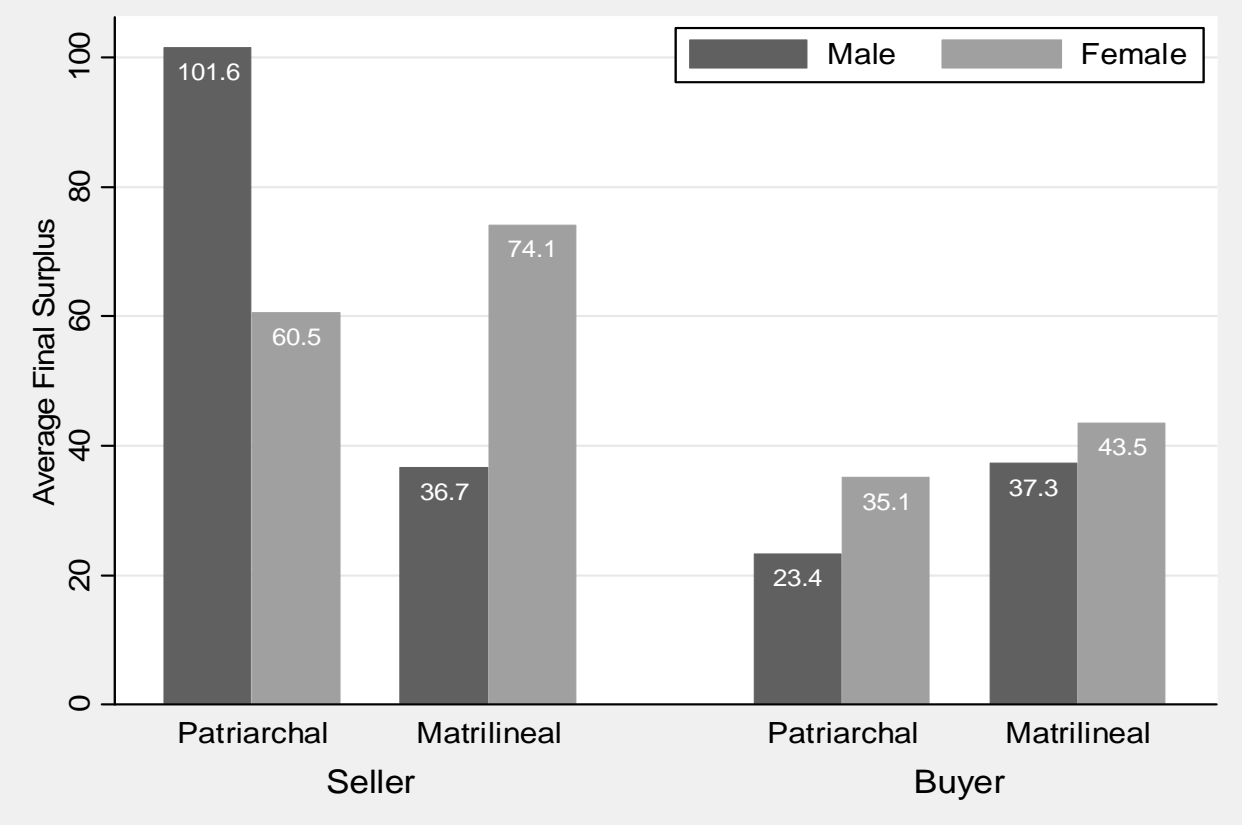

Note: Average final surplus is defined as final earnings for subjects in rupees. 
Figure 3: Desired surplus by gender and society (lab experiment)

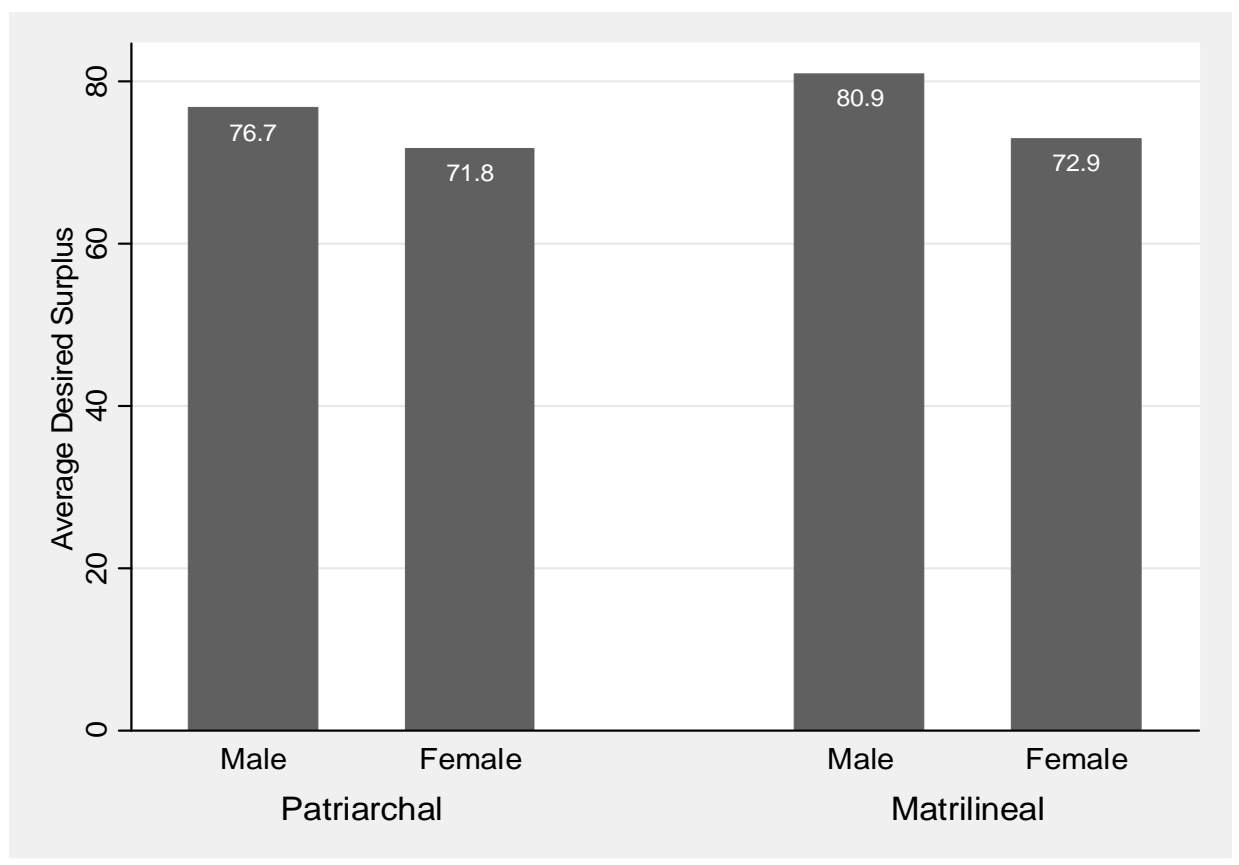

Note: Desired surplus is defined as the initial offered price for a seller in rupees, and 150 rupees minus initial offered price for a buyer.

Figure 4: Desired surplus by gender, society, and role (lab experiment)

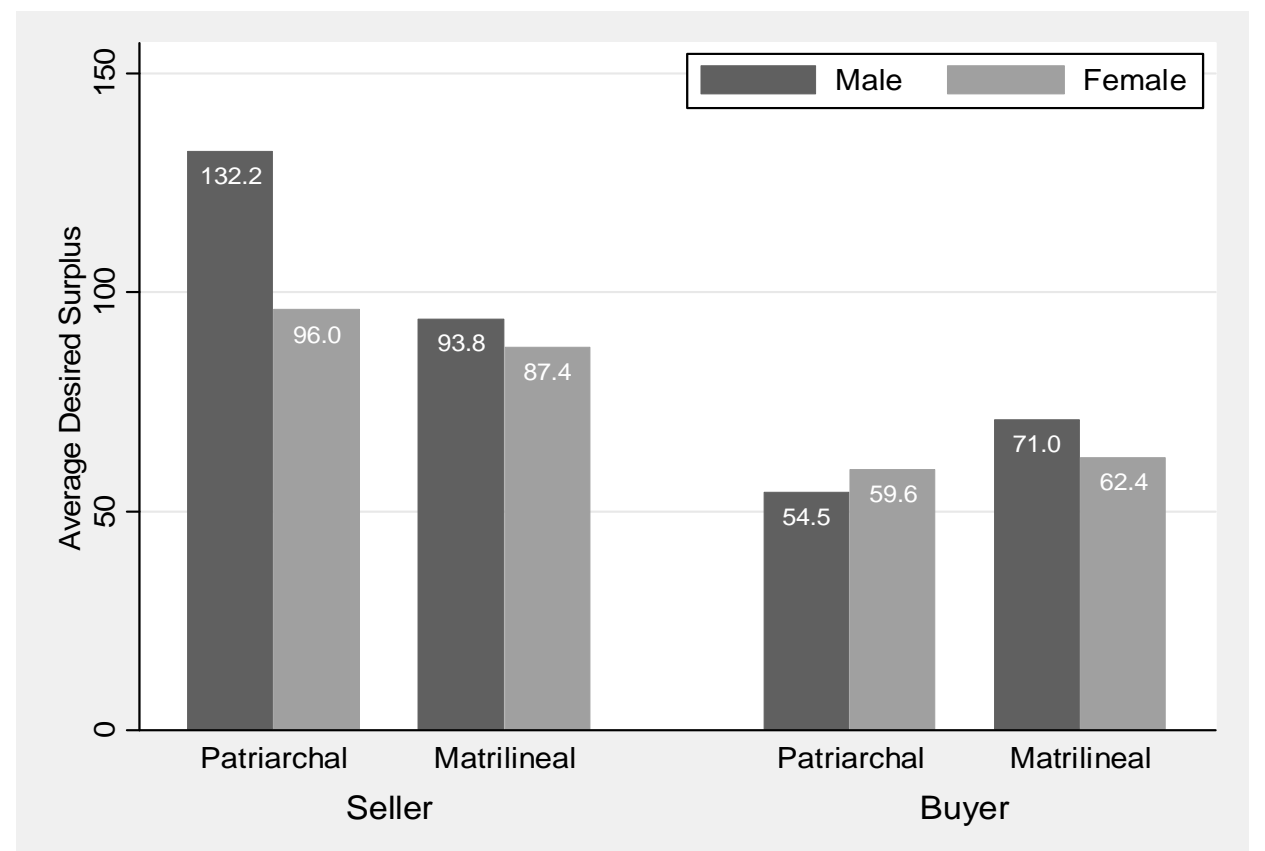

Note: Desired surplus is defined as the initial offered price for a seller, and 150 minus initial offered price for a buyer. 
Figure 5: Initial and final price in the market (field experiment)

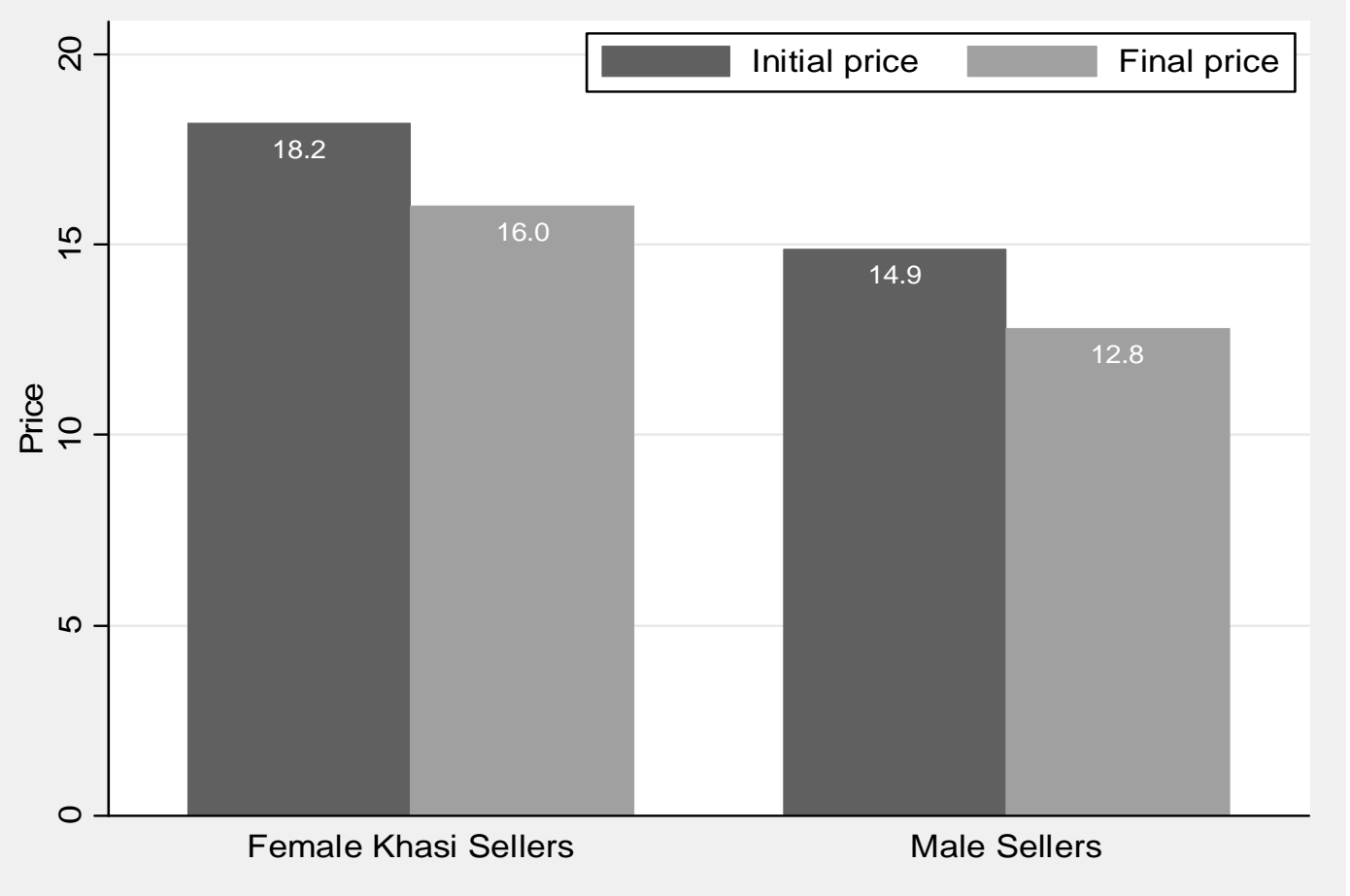




\section{TABLES}

Table 1: Frequency of rejections and being rejected (Lab experiment)

Patriarchal Male

$86.2 \%(0.6)[29]$

$75 \%(0.8)[28]$

$83.3 \%(0.7)[30]$

$50 \%(0.8)[36]$

Being

$74.1 \%(0.1)[27]$

$75 \%(0.1)[32]$

$69.2 \%(0.1)[39]$

$45.5 \%(0.1)[33]$

\section{Rejected}

Note: Std. errors in parentheses, and the total number of observations in brackets.

Table 2: Random effects regressions of final and initial prices (Market experiment)

\begin{tabular}{|c|c|c|c|c|c|c|c|c|}
\hline & \multicolumn{4}{|c|}{ Final price } & \multicolumn{4}{|c|}{ Initial price } \\
\hline & \multicolumn{2}{|r|}{ (1) } & \multicolumn{2}{|r|}{ (2) } & \multicolumn{2}{|r|}{ (3) } & \multicolumn{2}{|c|}{ (4) } \\
\hline & Coeff. & Std. Err. & Coeff. & Std. Err. & Coeff. & Std. Err. & Coeff. & Std. Err. \\
\hline Constant & 11.41 & $1.08 * * *$ & 10.94 & $1.48 * * *$ & 13.57 & $1.11 * * *$ & 13.44 & $1.50 * * *$ \\
\hline Matrilineal female & 4.41 & $1.52 * * *$ & 4.1 & $1.36 * * *$ & 4.43 & $1.58 * * *$ & 4.0 & $1.17 * * *$ \\
\hline Matrilineal male & 2.82 & $1.53 *$ & 3.0 & $1.36 * *$ & 2.59 & 1.58 & 2.55 & $1.17 * *$ \\
\hline $\begin{array}{l}\text { Controls for buyers } \\
\& \text { ethnicity pairings }\end{array}$ & No & & Yes & & No & & Yes & \\
\hline
\end{tabular}




\section{Appendix A.}

Table A1. Final surplus by gender, society, and role (Lab experiment)

\begin{tabular}{ccccc}
\hline & \multicolumn{2}{c}{ Patriarchal } & \multicolumn{2}{c}{ Matrilineal } \\
\hline \multirow{2}{*}{ Total } & $45.71(11.2)[56]$ & $43.58(60.3)[60]$ & $37.03(5.3)[69]$ & $56.38(4.8)[69]$ \\
Seller & $101.56(7.8)[16]$ & $60.50(10.2)[20]$ & $36.67(8.5)[30]$ & $74.14(7.7)[29]$ \\
Buyer & $23.38(13.9)[40]$ & $35.13(7.8)[40]$ & $37.31(6.7)[39]$ & $43.50(5.4)[40]$ \\
& & & & \\
\end{tabular}

Note: Std. errors in parentheses and number of observations in brackets. 
Table A2. Linear regression, dep. variable: Final Surplus (Lab experiment)

(1)

(2)

(3)

\begin{tabular}{|c|c|c|c|c|c|c|}
\hline & Coeff. & Std. Err. & Coeff. & Std. Err. & Coeff. & Std. Err. \\
\hline constant & 101.56 & $13.1 * * *$ & 105.80 & $14.3 * *$ & 121.23 & $18.2 * * *$ \\
\hline female & -41.06 & $17.5^{* *}$ & -41.75 & $17.6 * * *$ & -49.64 & $23.5^{* *}$ \\
\hline matrilineal & -64.90 & $16.2 * * *$ & -64.44 & $16.2 * * *$ & -89.657 & $23.5^{* * *}$ \\
\hline role & -78.19 & $15.5 * * *$ & -78.08 & $15.5 * * *$ & -77.48 & $15.4 * * *$ \\
\hline role $\times$ matrilineal & 78.83 & $20.0 * * *$ & 78.21 & $20.1 * * *$ & 76.90 & $20.2 * * *$ \\
\hline female $\times$ matrilineal & 78.53 & $22.2 * * *$ & 78.26 & $22.3 * *$ & 83.82 & $31.4 * * *$ \\
\hline role $\times$ female & 52.82 & $21.1 * *$ & 52.76 & $21.1^{* *}$ & 54.54 & $21.0^{* * *}$ \\
\hline $\begin{array}{l}\text { role } \times \text { matrilineal } \times \\
\text { female }\end{array}$ & -84.09 & $27.7 * * *$ & -83.39 & $27.8^{* *}$ & -83.73 & $27.6^{* * *}$ \\
\hline $\mathrm{T} 1$ & & & -7.41 & 8.5 & -32.19 & $18.4^{*}$ \\
\hline $\mathrm{T} 2$ & & & -3.2 & 8.6 & -17.88 & 19.0 \\
\hline $\mathrm{T} 1 \times$ female & & & & & 29.26 & 24.8 \\
\hline $\mathrm{T} 1 \times$ matrilineal & & & & & 35.90 & 24.3 \\
\hline $\mathrm{T} 1 \times$ female $\times$ matrilineal & & & & & -32.56 & 33.8 \\
\hline $\mathrm{T} 2 \times$ female & & & & & -15.67 & 25.2 \\
\hline $\mathrm{T} 2 \times$ matrilineal & & & & & 31.21 & 25.7 \\
\hline $\mathrm{T} 2 \times$ female $\times$ matrilineal & & & & & 20.77 & 34.4 \\
\hline
\end{tabular}

Note: $\mathrm{N}=254 .{ }^{* * *},{ }^{* *}$, and ${ }^{*}$ denote significance at the 1,5 , and 10 percent levels, respectively. $\mathrm{T} 1$ and $\mathrm{T} 2$ are dummies that capture the treatments in which subjects bargained on behalf of two people. Role takes on the value of one if the subject was in the role of a buyer, and zero if a seller.

$\mathrm{R}^{2}:(1)=0.138 ;(2)=0.141 ;(3)=0.176$ 
Table A3. Desired surplus and the difference between final and desired surplus by gender, society, and role (Lab experiment)

\begin{tabular}{|c|c|c|c|c|}
\hline \multirow[b]{3}{*}{ Desired Surplus } & \multicolumn{2}{|c|}{ Patriarchal } & \multicolumn{2}{|c|}{ Matrialineal } \\
\hline & Male & Female & Male & Female \\
\hline & $76.7(5.7) \quad[56]$ & $71.8(4.9) \quad[60]$ & $80.9(3.7)$ [69] & 72.9 (3.6) [69] \\
\hline Seller & $132.2(6.3)[16]$ & $96.0(8.7) \quad[20]$ & $93.8(6.9)[30]$ & $87.4(6.4) \quad[29]$ \\
\hline Buyer & $54.5(4.2) \quad[40]$ & $59.6(4.8) \quad[40]$ & $71.0(3.1)[39]$ & $62.4(3.5) \quad[40]$ \\
\hline $\begin{array}{l}\text { Final surplus- } \\
\text { desired surplus }\end{array}$ & $-31.0(10.9)[56]$ & $-28.2(6.4)[60]$ & $-43.9(5.8)[69]$ & $-16.5(4.5)$ [69] \\
\hline Seller & $-30.6(4.6) \quad[16]$ & $-35.5(11.6)[20]$ & $-57.2(9.4)[30]$ & $-13.3(7.4)[29]$ \\
\hline Buyer & $-31.1(15.1)[40]$ & $-24.5(7.7) \quad[40]$ & $-33.7(6.9)$ [39] & $-18.9(5.6)[40]$ \\
\hline
\end{tabular}

Note: Means as main number, standard errors in parentheses and number of observations in brackets. Desired surplus is defined as the initial offered price for a seller, and 150 minus initial offered price for a buyer. 
Table A4. Linear regression, dep. variable: Desired Surplus (Lab experiment)

(1)

(2)

(3)

\begin{tabular}{|c|c|c|c|c|c|c|}
\hline & Coeff. & Std. Err. & Coeff. & Std. Err. & Coeff. & Std. Err. \\
\hline constant & 132.19 & $7.3 * * *$ & 133.61 & $7.9 * * *$ & 121.23 & $18.2^{* * *}$ \\
\hline female & -36.19 & $9.8 * * *$ & -36.09 & $9.8 * * *$ & -44.09 & $13.2 * * *$ \\
\hline Matrilineal & -38.35 & $9.1 * * *$ & -39.19 & $9.0 * * *$ & -39.71 & $13.2 * * *$ \\
\hline role & -77.69 & $8.7 * * *$ & -77.17 & $8.6^{* * *}$ & -76.61 & $8.6 * * *$ \\
\hline role $\times$ matrilineal & 54.88 & $11.2^{* * *}$ & 55.62 & $11.1^{* * *}$ & 53.45 & $11.2 * *$ \\
\hline female $\times$ matrilineal & 29.77 & $12.5^{* *}$ & 31.84 & $12.4 * *$ & 39.72 & $17.6 * * *$ \\
\hline role $\times$ female & 41.31 & $11.8^{* * *}$ & 41.43 & $11.7^{* * *}$ & 40.73 & $11.8 * * *$ \\
\hline role $\times$ matrilineal $\times$ female & -43.54 & $15.6^{* * *}$ & -45.39 & $15.4^{* * *}$ & -43.16 & $15.5^{* * *}$ \\
\hline $\mathrm{T} 1$ & & & -2.28 & 4.7 & 2.15 & 10.3 \\
\hline $\mathrm{T} 2$ & & & -7.75 & 4.8 & -16.78 & 10.7 \\
\hline $\mathrm{T} 1 \times$ female & & & & & 10.27 & 13.9 \\
\hline $\mathrm{T} 1 \times$ matrilineal & & & & & -6.88 & 13.6 \\
\hline $\mathrm{T} 1 \times$ female $\times$ matrilineal & & & & & -5.42 & 19.0 \\
\hline $\mathrm{T} 2 \times$ female & & & & & 14.30 & 14.1 \\
\hline $\mathrm{T} 2 \times$ matrilineal & & & & & 14.97 & 14.4 \\
\hline $\mathrm{T} 2 \times$ female $\times$ matrilineal & & & & & -23.70 & 19.3 \\
\hline
\end{tabular}

Note: $\mathrm{N}=254{ }^{* * *},{ }^{* *}$, and $*$ denote significance at the 1,5 , and 10 percent levels, respectively. Desired surplus is defined as the initial offered price for a seller, and 150 minus initial offered price for a buyer. T1 and T2 are dummies that capture the treatments in which subjects bargained on behalf of two people. Role takes on the value of one if the subject was in the role of a buyer, and zero if a seller.

$\mathrm{R}^{2}:(1)=0.341 ;(2)=0.356 ;(3)=0.370$ 
Table A5. Difference between desired and actual surplus by gender, society, and role (Lab experiment)

\begin{tabular}{cccccc}
\hline & \multicolumn{3}{c}{ Patriarchal } & \multicolumn{2}{c}{ Matrilineal } \\
\hline \multirow{2}{*}{ Male } & Female & Male & Female \\
Selal & $-0.305(0.149)$ & {$[56]$} & $-0.284(0.206)[59]$ & $-0.522(0.06)[69]$ & $-0.194(0.07)[69]$ \\
Buyer & $-0.241(0.04)$ & {$[16]$} & $-0.268(0.131)[20]$ & $-0.619(0.08)[30]$ & $-0.115(0.10)[29]$ \\
\hline
\end{tabular}

Note: Main numbers calculated as the mean of (Final Surplus-Desired Surplus)/Desired Surplus. Desired surplus is defined as the initial offered price for a seller, and 150 minus initial offered price for a buyer.

$\mathrm{N}=253$ (One observation with desired surplus $=0$ was excluded). Standard errors in parentheses and number of observations in brackets.

Table A6. Probit regression, dep. variable: Reject (Lab experiment)

\begin{tabular}{lcc}
\hline & Coeff. & Std. Err. \\
\hline constant & 1.239 & $0.410^{* * *}$ \\
desired surplus (matched partner) & -0.006 & 0.004 \\
female & -0.772 & $0.461^{*}$ \\
matrilineal & -0.005 & 0.436 \\
& -0.162 & 0.586 \\
female $\times$ matrilineal & &
\end{tabular}

Note: $\mathrm{N}=94 . * * *, * *$, and $*$ denote significance at the 1,5 , and 10 percent levels, respectively. LR $\mathrm{Chi}^{2}=0.008$ 
Table A7. Probit regression, dep. variable: Being rejected (Lab experiment)

\begin{tabular}{lcc}
\hline & \multicolumn{1}{c}{ Coeff. } & Std. Err. \\
\hline constant & 0.525 & 0.357 \\
desired surplus & 0.002 & 0.003 \\
female & 0.028 & 0.355 \\
matrilineal & -0.159 & 0.337 \\
& -0.612 & 0.472 \\
female $\times$ matrilineal & & \\
\hline
\end{tabular}

Note: $\mathrm{N}=131 .{ }^{* * *},{ }^{* *}$, and $*$ denote significance at the 1,5 , and 10 percent levels, respectively. $\mathrm{LR} \mathrm{Chi}^{2}=0.008$

Figure 1A: Concessions (\%) after first offer being rejected (Lab experiment)

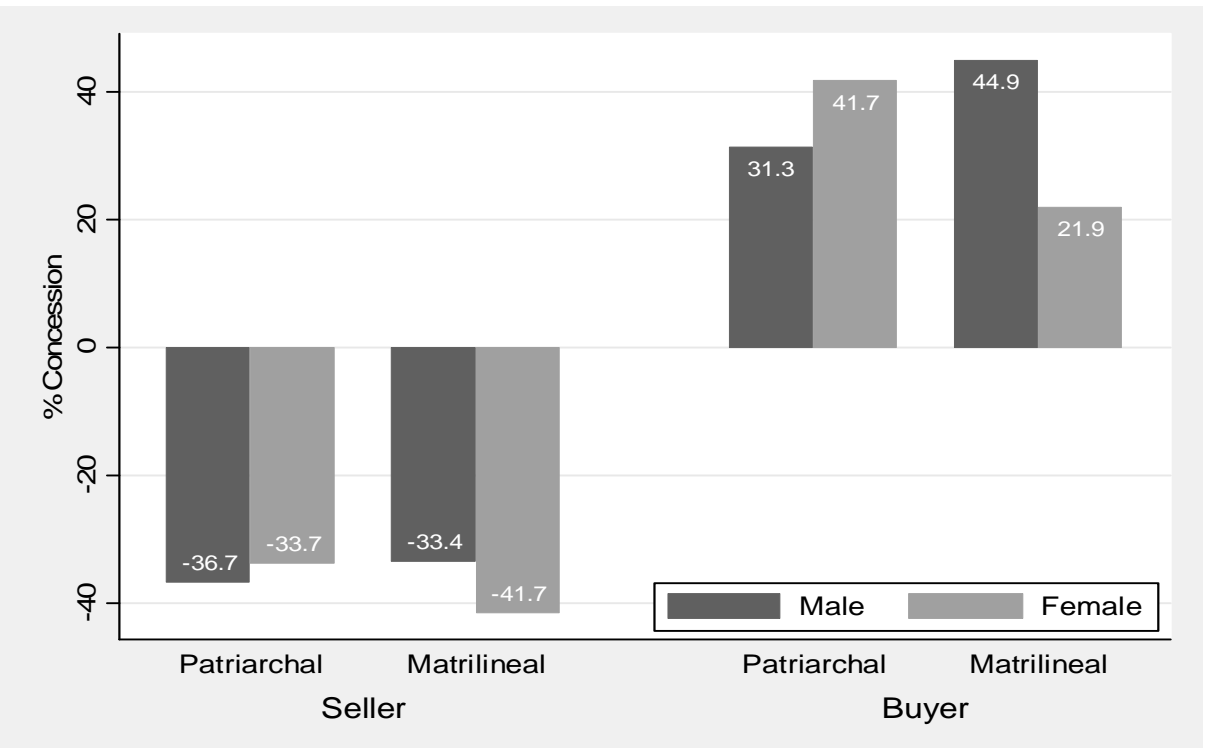

Note: Concession percentage is calculated as (First Offer-Second Offer)/First Offer*100. 
